\title{
AGREGAÇÃO DE VALOR EM EQÜINOS DA RAÇA CRIOULA: UM ESTUDO DE CASO
}

\author{
VALUE AGGREGATION IN CRIOULO HORSES: A CASE STUDY
}

\author{
Gianluppi, L.D.F. ${ }^{1 A}$, E.C. de Bortoli ${ }^{1}$, R. Schvarz Sobrinho ${ }^{1 B}$, T.F. Falcão ${ }^{1}$ e T.N. Silva ${ }^{1 C}$ \\ ${ }^{1}$ Centro de Estudos e Pesquisas em Agronegócios. CEPAN/UFRGS. Rua Washington Luís, 855. CEP 90010- \\ 460. Porto Alegre, RS. Brasil. Alugianluppi@terra.com.br, BRomeu@unicentro.br, Ctnsilva@ea.ufrgs.br
}

\section{PaLAVRAS ChaVE ADICIONAIS}

Prêmio Freio de Ouro. Diferenciação.

\section{RESUMO}

Com o melhoramento da raça, a admiração pelos cavalos Crioulos foi se tornando um vantajoso investimento. O Prêmio Freio de Ouro se tornou um dos instrumentos mais completos para se avaliar o potencial de lucratividade de um animal. Assim, o objetivo deste estudo foi retratar a agregação de valor em cavalos Crioulos destinados à competição. Esse objetivo foi alcançado pelo estudo de caso do vencedor do Prêmio Freio de Ouro 2006, Ganadero Da Harmonia, utilizando entrevistas e pesquisas em websites relacionados à raça em análise. Encontrou-se que a agregação de valor se inicia pela genealogia do animal, seguida pelo adestramento e, como fator mais importante, a premiação no Freio de Ouro. Conclui-se que a diferenciação do animal se dá pelo aprimoramento das qualidades já existentes e é fundamental para a agregar valor.

\section{SUMMARY}

With the improvement of breed, the admiration for Crioulo horses became a profitable investment. In search of the best animal to invest these values the Freio de Ouro award became the most complete instrument. The objective of this study is to portray how value is agregated in Crioulo horses meant specially for competition. This objective was accomplished by the case study of the winner of the Freio de Ouro 2006 competition, Ganadero Da Harmonia, using interviews and searchs in websites about Crioulo horses. As a result if was found that value agregation starts from the genealogy of the animal, followed by the training and, as a main factor is the premium of

Recibido: 19-4-07. Aceptado: 21-2-08.

\section{AdDitional KeYWORDS}

Freio de Ouro award. Differentiation.

Freio de Ouro. It should be concluded that the animal differentiation happens with horse's qualities improvement and it is fundamental to aggregate value.

\section{INTRODUÇÃO}

Os cavalos da raça Crioula têm papel importante na cultura do Rio Grande do Sul, Brasil, por se entender que esses animais são genuinamente originados na região do Pampa. Com o passar dos anos, a admiração pelos Crioulos tem se tornado um investimento rentável. Conforme a Associação Brasileira de Criadores de Cavalos Crioulos (ABCCC), em 2005, o valor médio de um animal da raça foi de US\$5345,6, valor $110 \%$ maior que a média de 2002 (US\$2534,5). Ressalta-se que animais que participam das últimas etapas no Prêmio Freio de Ouro têm crescimento de valores mais expressivos, caso da égua Butiá Luiza, campeã do Freio de Ouro 2002, que foi vendida em 2005 por US\$186 174,3.

O Prêmio Freio de Ouro é uma prova para eqüinos da raça Crioula que avalia a morfologia, verificando o enquadramento do animal nos padrões da raça, e a funcionalidade, avaliando o desempenho nos serviços de campo, e é promovida há mais 25 anos pela ABCCC. De acordo com o regulamento do Freio de Ouro, estipulado por ABCCC (2006), o objetivo de tal prova 
GIANLUPPI, BORTOLI, SCHVARZ SOBRINHO, FALCÃOE SILVA

é difundir, fomentar e valorizar a raça, além de utilizá-la como uma ferramenta de seleção de animais. Nessa competição, os eqüinos da raça são submetidos a três etapas: provas credenciadoras, provas classificatórias e prova final do Freio de Ouro.

As provas credenciadoras iniciam logo que acaba um ciclo da competição, isto é, após a premiação de um animal na Exposição Agropecuária Internacional (Expointer), sediada em Esteio, Rio Grande do Sul. Os animais de maiores notas de cada credenciadora são selecionados para as provas classificatórias, que ocorrem em quatro estados brasileiros, sendo o Rio Grande do Sul o com maior número de provas, além de uma na Argentina e outra no Uruguai. A prova final do Freio de Ouro é disputada entre todos os concorrentes classificados na etapa anterior, no primeiro final de semana da Expointer com programação definida pela $\mathrm{ABCCC}$.

Com o passar das edições, o Freio de Ouro foi se tornando um veículo de seleção dos melhores exemplares da raça, o que acabou desenhando um perfil de animal ideal. Desta forma, esta pesquisa utiliza o método do estudo de caso do vencedor do Prêmio Freio de Ouro 2005/2006, o cavalo Ganadero Da Harmonia, para retratar diferenciação entre animais da raça Crioula, procurando responder a seguinte pergunta: como se dá a agregação de valor em cavalos da raça Crioula?

Para tanto, utiliza-se base teórica acerca de cadeia de valor, conjunto de atividades que agregam valor a um produto, e estratégia de diferenciação, que busca tornar o produto único, agregando-lhe valor. Assim, esse trabalho se propõe a retratar a agregação de valor em cavalos da raça Crioula em animais destinados à competição.

\section{MATERIALE MÉTODOS}

Para observar a diferenciação entre eqüinos da raça Crioula e responder ao modo como se dá a agregação de valor em animais dessa raça, foi utilizado um estudo de caso com o vencedor do Prêmio Freio de Ouro 2005/2006, o cavalo Ganadero Da Harmonia.

O estudo de caso (Gil, 2006) consiste no estudo profundo de um objeto, de maneira que permita seu amplo e detalhado conhecimento. Os dados nesse tipo de estudo podem ser obtidos mediante análise de documentos, entrevistas, depoimentos pessoais, observação espontânea, observação participante e análise de artefatos físicos.

Assim, a coleta de dados se deu através da Internet e de entrevistas. As informações obtidas nos websites relacionados à raça Crioula auxiliaram na construção das entrevistas, já que disponibilizam diversas informações sobre a história, a genealogia da raça, o treinamento dos animais e sobre o Prêmio Freio de Ouro. Com as perguntas formuladas foram realizadas as duas entrevistas: uma com o síndico do Condomínio Ganadero (o cavalo Ganadero Da Harmonia possui 11 co-proprietários), Sr. José Luís Gomes, no dia 08 de novembro de 2006, e a segunda com o Sr. Luís Centeno do Amaral, historiador da raça crioula, professor da Universidade Federal de Pelotas, UFPEL, Rio Grande do Sul, no dia 07 de novembro de 2006. As informações obtidas através das entrevistas e das consultas à Internet serviram de base para chegar à estrutura de agregação de valor apresentada na seção seguinte.

\section{RESULTADOSEDISCUSSÃO}

Nessa seção, são apresentadas considerações sobre a agregação de valor em um animal da raça Crioula destinado à competições. Observa-se que a agregação de valor é iniciada com uma genealogia reconhecida, passando pelos trabalhos na cabanha (local especializado na criação de animais de algumas espécies) e no centro de treinamento, sendo finalizada nas competições. $\mathrm{O}$ lazer e trabalho, juntamente com a propriedade, também figuram como elementos im- 
portantes nesse processo.

Genealogia. Ganadero Da Harmonia é filho de Muchacho de Santa Angélica com BT Dádiva do Junco. Concentra em sua genealogia, genética dos principais representantes da raça crioula na América do Sul. Em sua ascendência materna se encontra $\mathrm{La}$ Invernada Hornero, seu avô, além de outros importantes animais dentro da raça como: La Invernada Aniversário, Sorro Campeiro e Tren Tren Arrebol. Em sua ascendência paterna, também encontramos animais de destaque como: Santa Elba Señuelo, seu avô, e Las Mercedes Taco, seu bisavô.

Para Luís Centeno do Amaral ao se unir a docilidade e função presentes em Santa Elba Señuelo com a morfologia e a função de La Invernada Hornero, só se pode esperar bons resultados. Além disso, a mãe de Ganadero Da Harmonia, BT Dádiva do Junco, reúne ainda genética de La Invernada Aniversário e Sorro Campeiro, ou seja, genéticas presentes em mais doze premiações do Freio de Ouro. A figura 1 ilustra o caminho da diferenciação do animal.

Cabanha. Na Cabanha Harmonia, Ganadero Da Harmonia foi domado de forma tradicional (adestramento que leva em conta conceitos medianos de bem-estar animal) para cavalos Crioulos e iniciado no trabalho de campo. Demonstrou ser um animal dócil e sujeito à doma, requisitos básicos para se ter um bom cavalo para competições. O importante, nesta fase da vida do animal, é receber um bom manejo. Nesse momento, os animais destaques são identificados pelos cabanheiros, para posteriormente serem treinados e tornarem-se vencedores da raça.

Para se obter bons resultados com o cavalo, ainda na cabanha, é indispensável a manutenção de uma rotina que engloba: alimentação equilibrada (composta de ração e pasto à vontade), horários fixos para alimentação e trabalho de qualidade e em quantidade adequada, além de ser fundamental, a higiene do ambiente e docilidade no manejo do animal.

Centro de treinamento. Aos sete anos de idade, em 2002, foi enviado ao Centro de Treinamento Zeca Macedo (conhecido pela sua excelência e gerido pelo ginete que conduziu o cavalo na competição de 2005/ 2006, pois demonstrou ter alto potencial para disputar as provas da raça), onde tem recebido cuidados veterinários e treinamentos específicos para concursos.

Competições. A participação de Ganadero Da Harmonia no Prêmio Freio de Ouro iniciou em 2004, quando conquistou o quarto lugar, confirmando sua potencialidade expressada após a doma e demonstrando que o trabalho de Zeca Macedo estava no caminho certo. Em 2005, conquistou o Freio de Bronze e, em 2006, tornouse vencedor.

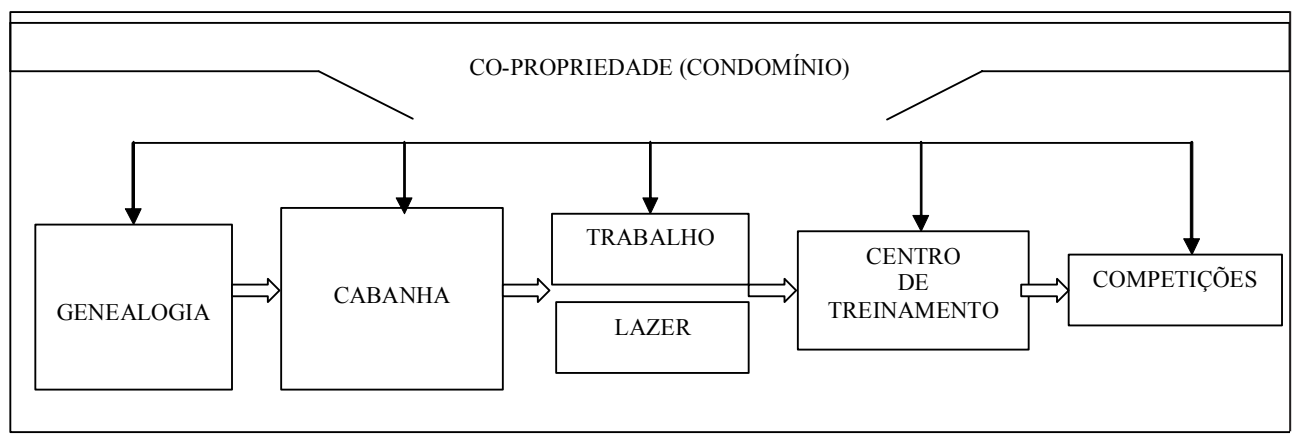

Figura 1. Fases do processo de formação e valoração do produto. (Stages of product development and value agregation processes). 
Questionado sobre a participação do animal no ciclo (2006/2007), o Síndico declarou que os proprietários decidiram em não colocá-lo na disputa da competição, objetivando manter sua imagem como vencedor do Freio de Ouro 2006 e conservar o valor agregado. Daqui em diante, Ganadero não será mais tratado como um cavalo para competições, pois já cumpriu sua função como vencedor e servirá como reprodutor ou para eventuais atividades de lazer, afirma José Luís Gomes.

Trabalho e lazer. No processo de acompanhamento e avaliação da genealogia, morfologia e qualificação individual em aspectos funcionais, os cavalos desempenham trabalhos no manejo de animais nas fazendas ou são utilizados para fins de lazer, atividade que tem crescido nos últimos anos.

Co-propriedade (condomínio). É uma alternativa que tem possibilitado a aquisição de animais com maior valor agregado por cabanhas de menor porte e tradição. Os condôminos supervisionam todo o processo de qualificação dos animais: da genealogia, permeando por estratégias de marketing, até a remuneração do capital investido. A propriedade de Ganadero Da Harmonia é de um grupo de 11 proprietários que o adquiriram em novembro de 2005.

No ano da formação do condomínio, o cavalo estava avaliado em US\$73732,7. Após a conquista do Freio de Ouro 2005/2006, seu valor estimado para realização do seguro foi de US $\$ 138248,8$. No entanto, o Síndico afirma que o cavalo não tem preço de mercado, pois o mesmo não está disponível à comercialização. No mesmo sentido foram os preços das coberturas, passando de cer-

\section{BIBLIOGRAFIA}

ABCCC. 2005. Ano de bons negócios para a raça Crioula.Pelotas/Rio Grande do Sul/Brasil, 30 de dezembro de 2005. Disponível em: http://www. abccc.com.br/notícia.php?T0=9. Acesso em: 5 de novembro de 2006. ca de US\$1382,5 para US\$3870,9 quando chegou ao ápice de seu valor.

Resumindo, a concepção do produto passa pelo processo de apuração da raça genealogia-, tratamento na cabanha nutrição, manejo, educação, treinamento, etc-, lapidação do produto no centro de treinamento e a destinação final para trabalho, lazer ou competições/concursos/ provas. Todas as fases do processo supervisionadas pelo proprietário ou condomínio.

Portanto, o processo de preparação do animal e apresentação ao mercado (competições) de produto com qualidade, diferenciado em termos morfológicos, funcionais e de marketing são linguagens de negócios já incorporadas no agronegócio e no meio empresarial que lida com a raça Crioula com fins econômicos e na manutenção das tradições regional.

Em conclução, a agregação de valor em cavalos da raça Crioula é resultante da genealogia, seguido do bom manejo e da doma realizados na cabanha. $\mathrm{O}$ treinamento feito no centro especializado permite que haja maior agregação de valor ao animal e as suas coberturas, por fim, e como fator mais importante, a premiação no Freio de Ouro. Esse é o caminho mais eficiente para agregação de valor em um animal Crioulo, contudo características como genealogia $\mathrm{e}$ morfologia precisam ser observadas para que a diferenciação seja exitosa. Para que a raça alcance maior valor agregado, sugerese que os cruzamentos de animais sejam preparados de forma a conservar a boa genética, utilizando-se animais com genealogia premiada.

ABCCC. 2006. Disponível em: http://www. abccc.com.br. Acesso em: 1 de novembro de 2006.

Gil, A. C. 2006. Como elaborar projetos de pesquisa. Atlas. São Paulo. 175 p. 